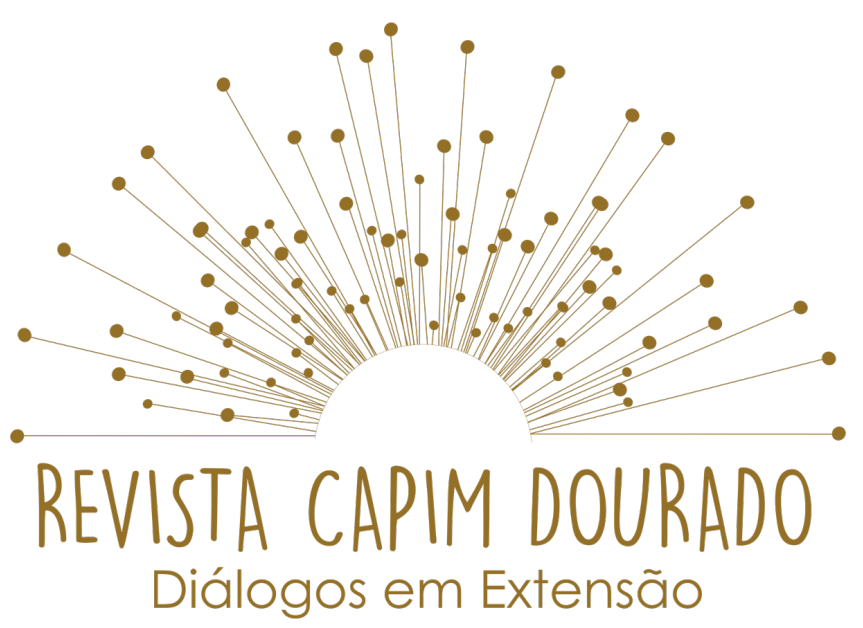

ISSN n² 2595-7341

Vol. 3, n. 1, Janeiro-Abril, 2020

DOI: http://dx.doi.org/10.20873/uft.2595-7341.2020v3n1p111

\title{
OFICINAS DE ORIENTAÇÃO EDUCACIONAL E PROFISSIONAL PARA JOVENS ESTUDANTES DE UMA ESCOLA PÚBLICA
}

\section{EDUCATIONAL AND PROFESSIONAL ORIENTATION WORKSHOPS FOR YOUNG STUDENTS IN A PUBLIC SCHOOL}

\section{TALLERES DE ORIENTACIÓN EDUCATIVA Y PROFESIONAL PARA ALUMNOS JÓVENES DE UNA ESCUELA PÚBLICA}

\section{Yasmin Coelho dos Santos Parreão ${ }^{1}$ Ladislau Ribeiro do Nascimento ${ }^{2}$}

\section{RESUMO}

Este trabalho relata uma ação de extensão universitária promovida em uma escola pública localizada em Miracema do Tocantins - TO. Realizamos oficinas de intervenção psicossocial com o intuito de promover práticas de cuidado de si no contexto escolar. Contamos com a participação de um grupo de vinte e três estudantes com histórico de dificuldades de aprendizagem. A intervenção foi desenvolvida em oito encontros semanais, cada um com carga horária de duas horas. As atividades abrangeram rodas de conversa sobre experiências cotidianas, análises coletivas acerca da realidade social, oficinas de artesanato e de Capoeira de Angola, leituras de poesias, e troca de informações sobre áreas de formação e de atuação profissional. Os/as participantes foram mobilizados/as

\footnotetext{
${ }^{1}$ Graduanda em Psicologia pela Universidade Federal do Tocantins (UFT), Miracema do Tocantins - TO. yasminparreao@gmail.com.

2 Doutor em Psicologia Social pela Universidade de São Paulo (USP). Mestre em Psicologia Social pela Pontifícia Universidade Católica da São Paulo. Professor Adjunto no Curso de Psicologia da Universidade Federal do Tocantins (UFT), Miracema do Tocantins - TO, ladislaunascimento@uft.edu.br
} 


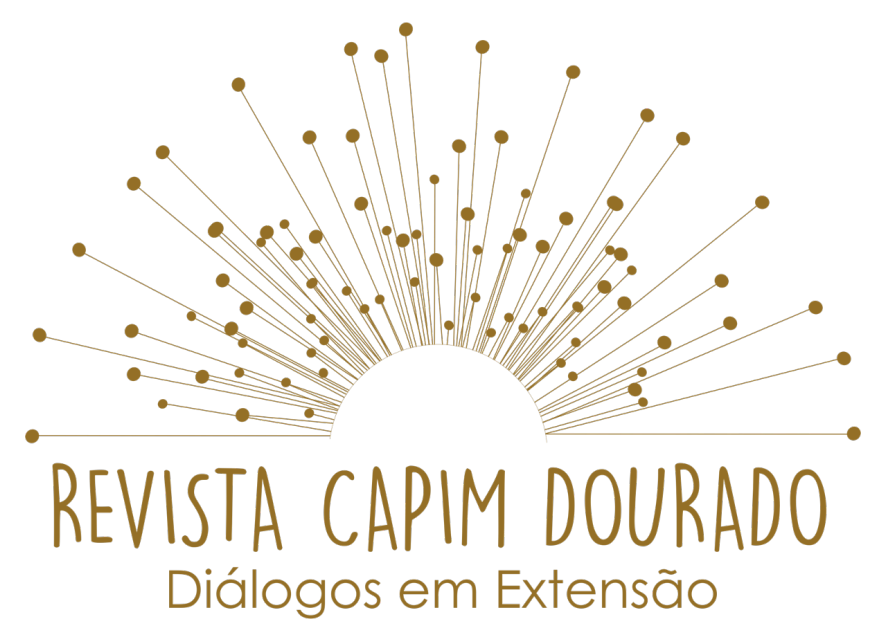

ISSN n² 2595-7341

Vol. 3, n. 1, Janeiro-Abril, 2020

DOI: http://dx.doi.org/10.20873/uft.2595-7341.2020v3n1p111

pelo (re)conhecimento de habilidades e competências desenvolvidas ao longo de suas trajetórias escolares.

PALAVRAS-CHAVE: Extensão Universitária. Escola Pública. Intervenção Psicossocial. Psicologia Escolar e Educacional.

\section{ABSTRACT}

This work reports a university extension action promoted in a public school located in Miracema do Tocantins - TO. We carry out psychosocial intervention workshops in order to promote self-care practices in the school context. We have the participation of a group of twenty-three students with a history of learning difficulties. The intervention was developed in eight weekly meetings, each with a two-hour workload. The activities included conversation circles about everyday experiences, collective analysis of the social reality, handicraft and Capoeira workshops in Angola, poetry readings, and exchange of information on areas of training and professional performance. The participants were mobilized by the (re) knowledge of skills and competences developed throughout their school trajectories.

KEYWORDS: University Extension. Public school. Psychosocial Intervention.

School and Educational Psychology.

\section{RESUMEN}

Este trabajo reporta una acción de extensión universitaria promovida en una escuela pública ubicada en Miracema do Tocantins - TO. Realizamos talleres de intervención psicosocial con el fin de promover prácticas de autocuidado en el contexto escolar. Contamos con la participación de un grupo de veintitrés 


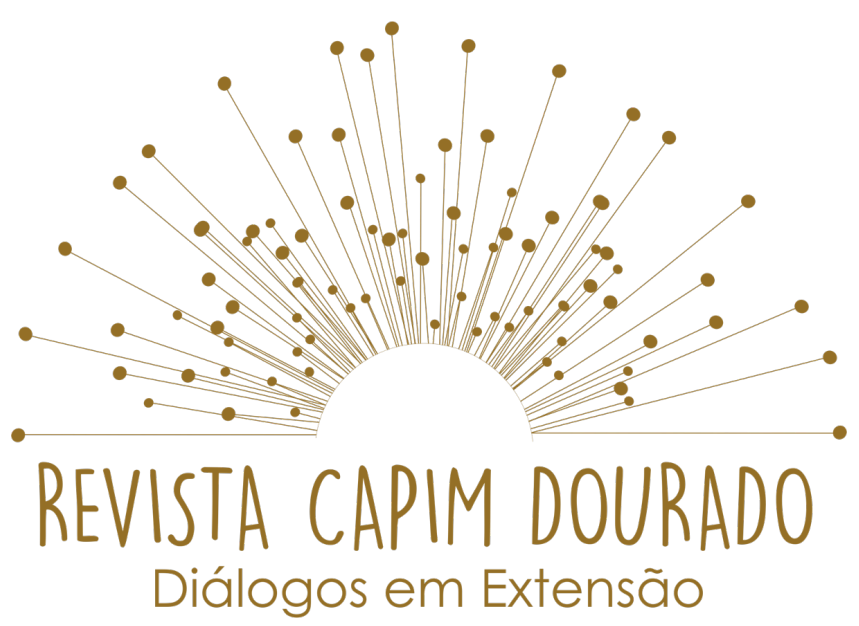

ISSN n² 2595-7341

Vol. 3, n. 1, Janeiro-Abril, 2020

DOI: http://dx.doi.org/10.20873/uft.2595-7341.2020v3n1p111

alumnos con historial de dificultades de aprendizaje. La intervención se desarrolló en ocho reuniones semanales, cada una con una carga de trabajo de dos horas. Las actividades incluyeron círculos de conversación sobre vivencias cotidianas, análisis colectivo de la realidad social, talleres de artesanía y Capoeira en Angola, lecturas de poesía e intercambio de información sobre áreas de formación y desempeño profesional. Los participantes fueron movilizados por el (re) conocimiento de habilidades y competencias desarrolladas a lo largo de sus trayectorias escolares.

PALABRAS CLAVE: Extensión Universitaria. Escuela pública. Intervención psicosocial. Psicología escolar y educativa.

Recebido em: 01.10.2019. Aceito em: 09.10.2019. Publicado em: 01.01.2020. 


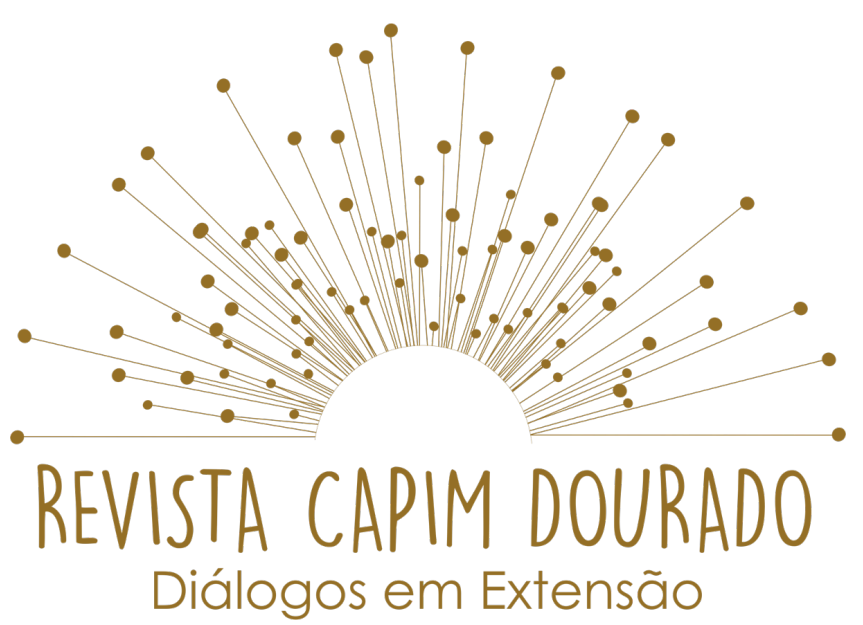

ISSN n² 2595-7341

Vol. 3, n. 1, Janeiro-Abril, 2020

DOI: http://dx.doi.org/10.20873/uft.2595-7341.2020v3n1p111

\section{INTRODUÇÃO}

As práticas de extensão universitária cumprem papel importante ao viabilizar conexões entre universidade e comunidade. Elas propiciam oportunidades ao desenvolvimento acadêmico e científico de professores e estudantes ao transcender limites didático-pedagógicos dos modelos tradicionais de ensino.

Mediante tal compreensão, propusemos uma prática de intervenção em Psicologia Escolar e Educacional. De um modo mais específico, oferecemos orientação educacional e profissional para jovens estudantes matriculados em uma escola pública.

As práticas de orientação foram realizadas por meio de uma proposta de intervenção psicossocial, tendo como principais objetivos: promover práticas de cuidado de si no contexto escolar, provocar rupturas no cotidiano institucional caracterizado pela repetição e pelo acirramento de tensões nas relações interpessoais.

\section{METODOLOGIA}

O projeto foi desenvolvido por meio de oficinas de intervenção psicossocial (SARRIERA, CÂMARA, BERLIM, 2006; NEIVA, 2010). Realizamos oito encontros, cada um com carga horária de duas horas. As ações foram coordenadas por um docente e tiveram apoio de uma estudante, bolsista de extensão, ambos do curso de Psicologia da Universidade Federal do Tocantins 


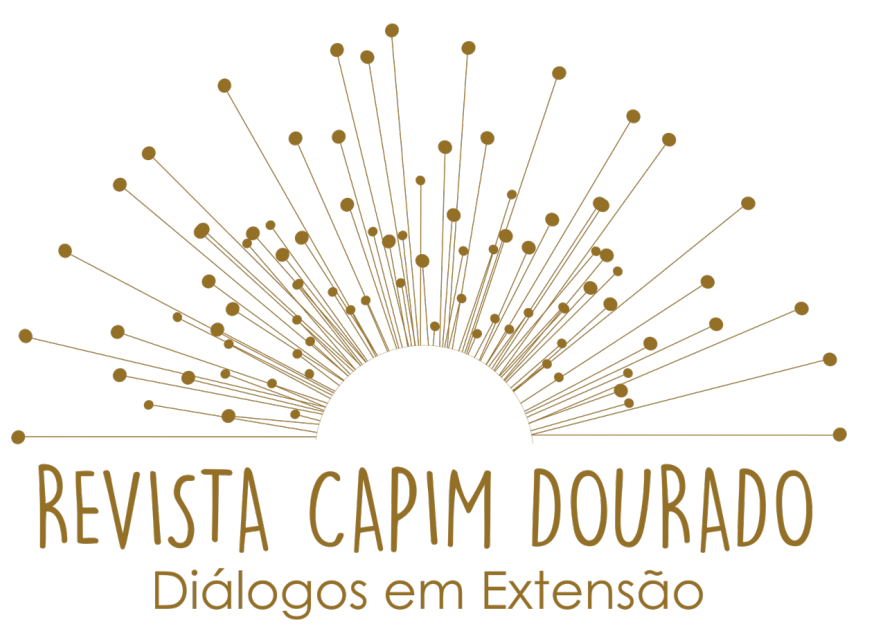

ISSN n² 2595-7341

Vol. 3, n. 1, Janeiro-Abril, 2020

DOI: http://dx.doi.org/10.20873/uft.2595-7341.2020v3n1p111

(UFT). A equipe também contou com a participação pontual estudantes voluntários. O público-alvo foi um grupo de vinte e três estudantes com idades entre 18 e 30 anos de idade, vinculados a uma escola pública situada em Miracema do Tocantins - TO, matriculados em diferentes séries dos níveis de ensino fundamental II e médio, na modalidade de Educação de Jovens e Adultos (EJA).

As ações foram realizadas no primeiro semestre de 2018, por meio de atividades como: reprodução vídeo sobre cotidiano escolar; audição de música sobre expectativas de vida; aplicação de inventários acerca de habilidades e competências vinculadas aos processos formativos; confecção de artesanatos; vivência em oficina sobre Capoeira Angola; leitura de versos e poesias sobre o sentido da vida; devolutivas aos participantes e aos professores.

\section{RESULTADOS E DISCUSSÃO}

O primeiro encontro foi destinado à apresentação do plano de oficinas. Esta atividade aproximou equipe e participantes. O momento foi importante para a formação de um vínculo que seria fundamental durante todo o processo de intervenção.

No segundo encontro, reproduzimos trechos do documentário Pro Dia Nascer Feliz (JARDIM, 2006), além da versão integral da música A Vida é Desafio (RACIONAIS MC's, 1997). Ouvimos e falamos sobre a realidade social. Discorremos sobre impasses e desafios a serem superados pelos participantes, na busca de possibilidades para construírem projetos de vida que se 


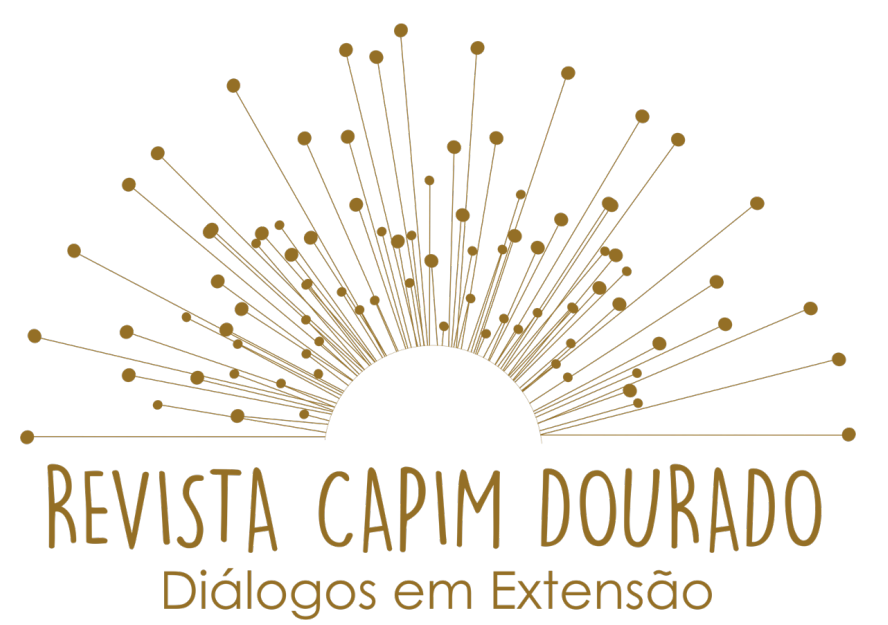

ISSN n² 2595-7341

Vol. 3, n. 1, Janeiro-Abril, 2020

DOI: http://dx.doi.org/10.20873/uft.2595-7341.2020v3n1p111

contraponham aos destinos mais comuns de pessoas daquele contexto. Em geral, os jovens da região com ensino médio completo estão inseridos no mundo do trabalho em condições precárias. Histórias de desenvolvimento acadêmico e profissional associados à formação de nível superior não são frequentes. Naquele território, vale frisar, projetar-se no futuro implica na transposição de limites impostos pela dureza de um tempo calcado na pobreza e nas restrições que dela derivam.

O terceiro encontro abriu espaço para abordarmos temas como diversidade e projeto de vida. O encontro teve início com a apresentação de figuras da Gestalt (figura-fundo). Em seguida, aplicamos as atividades Roda da Aprendizagem e Inventário das Frases Incompletas (BOHOSLAVSKY, 1993), respectivamente. A proposta mostrou-se relevante ao fortalecimento de vínculos entre participantes e membros da equipe.

No quarto encontro realizamos uma oficina de artesanatos e devolvemos os resultados da Roda da Aprendizagem. Confeccionamos pulseiras de lã com o auxílio voluntário de uma acadêmica do curso de Psicologia da UFT. Sentimos a potência da criatividade e da inventividade nos processos interventivos (KASTRUP, 2001). Elas operaram como vetores de subjetivação (DELEUZE; GUATTARI, 1996) através dos quais as singularidades se expressaram para afirmar o valor da diferença, na contramão das recorrentes práticas homogeneizantes implementadas nos espaços escolares.

O quinto encontro foi dedicado à oficina sobre Capoeira Angola. O trabalho contou com a participação de um acadêmico do Curso de Pedagogia da 


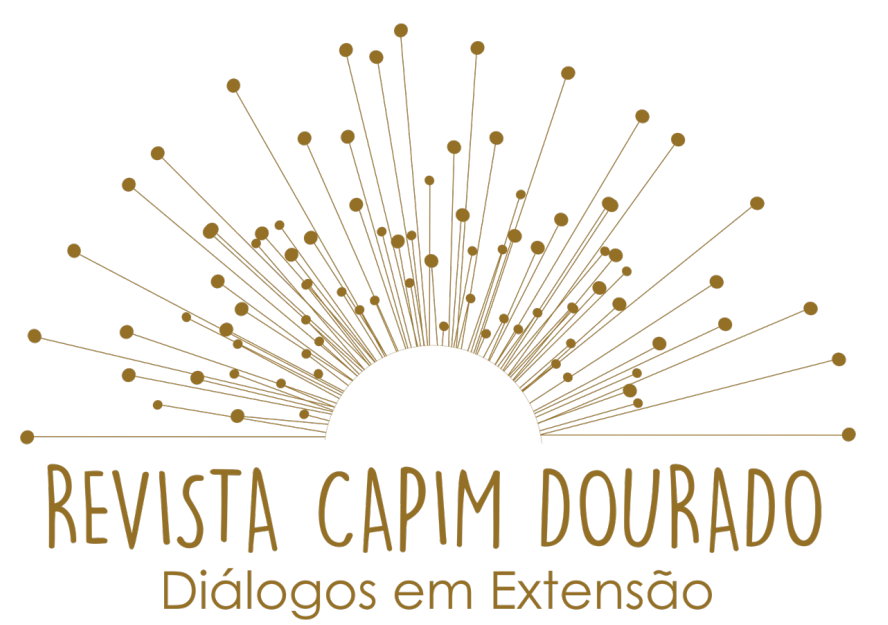

ISSN n² 2595-7341

Vol. 3, n. 1, Janeiro-Abril, 2020

DOI: http://dx.doi.org/10.20873/uft.2595-7341.2020v3n1p111

UFT. Por mais que muitos jovens tenham se envolvido com a atividade, uma auxiliar da equipe observou o fato de nenhuma jovem do sexo feminino ter participado. Esta observação fomentou a problematização sobre a reprodução do machismo e do sexismo no cotidiano.

No sexto encontro fizemos leituras versos e poesias. A atividade foi moderada por uma extensionista em companhia de uma acadêmica do Curso de Psicologia da UFT. Cada participante teve oportunidade para expressar sentimentos e pensamentos vinculados às experiências de vida compartilhadas entre membros do grupo.

No sétimo encontro aplicamos uma atividade para identificar habilidades e preferências relacionadas aos diferentes campos de atuação profissional. Em seguida, procuramos associá-las às distintas formações e carreiras. Notou-se distanciamento dos participantes em relação aos temas abordados. As falas eram esparsas e indicavam sinais de fragilização da escola enquanto instituição de fomento ao desenvolvimento pessoal e profissional.

O oitavo e último encontro foi destinado para a devolutiva acerca de todas as atividades desenvolvidas nas demais sessões. O projeto foi finalizado, em um clima de confraternização, com música ao vivo, salgadinhos e refrigerantes, na presença de membros da equipe gestora da escola. Os participantes falaram sobre como as atividades haviam sido experimentadas desde o primeiro encontro.

\section{CONSIDERAÇÕES FINAIS}




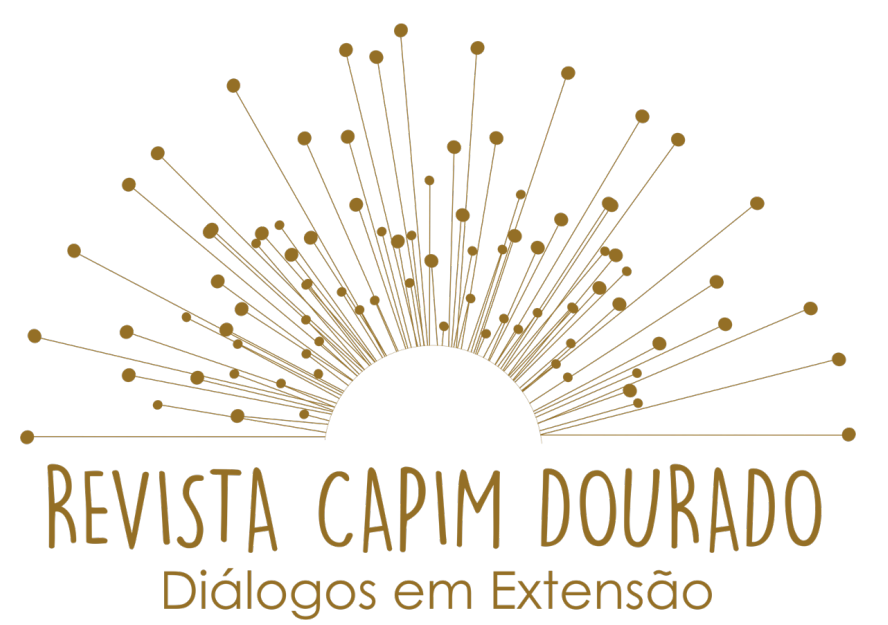

ISSN n² 2595-7341

Vol. 3, n. 1, Janeiro-Abril, 2020

DOI: http://dx.doi.org/10.20873/uft.2595-7341.2020v3n1p111

O projeto viabilizou a criação de novos espaços e tempos no cotidiano institucional. As recorrentes práticas de controle e de assujeitamento perpetradas na escola foram confrontadas pela força da inventividade.

$O$ engajamento demonstrado pelos participantes foi fundamental para o alcance dos resultados do trabalho. De um modo geral, todos se envolveram de modo significativo com o trabalho. Equipe gestora, professoras e professores, alunas e alunos do grupo encaminhado para as oficinas, bem como equipe de execução, acadêmicas e acadêmicos voluntários.

Constatamos sinais de fragilização da escola em meio aos desafios para o cumprimento do papel de formar cidadãos e de prepara-los para os mais diversos campos de atuação no mundo do trabalho.

Durante a intervenção, o coordenador do projeto foi convidado pela equipe gestora para a realização de ações voltadas ao corpo docente. Aos pedidos somaram-se queixas sobre o que fora definido como uma "sensação de impotência" compartilhada pela maior parte do corpo docente.

Alguns professores mostraram-se céticos em relação à possibilidade de estudantes demonstrarem envolvimento com as atividades e práticas pedagógicas. Outros, por sua vez, queixaram-se das precárias condições laborais encontradas na escola.

A demanda pela realização de intervenções para os professores, e as produções decorrentes das ações destinadas aos participantes do projeto aqui relatado, apontam para a necessidade de disseminarmos outras práticas interventivas nos espaços escolares. 


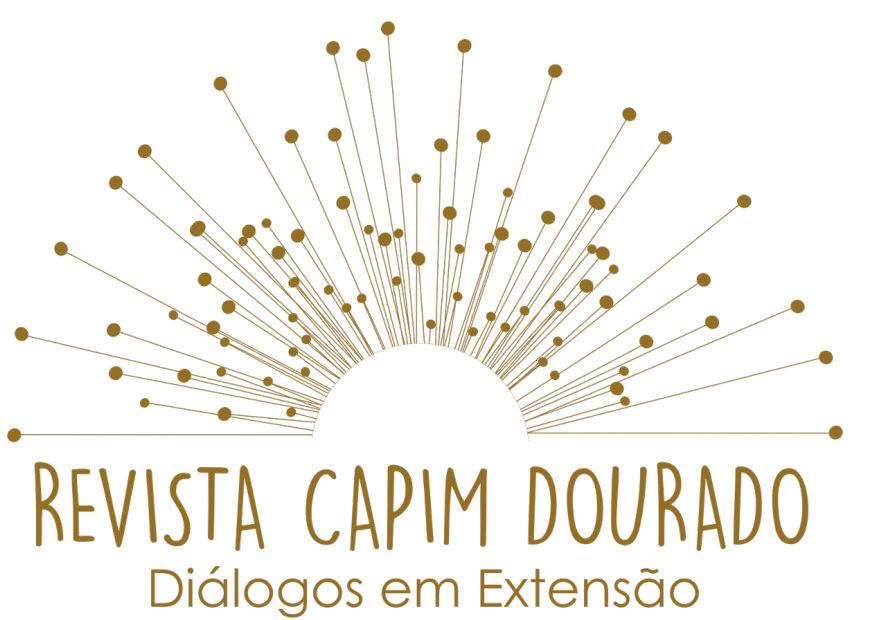

ISSN n² 2595-7341

Vol. 3, n. 1, Janeiro-Abril, 2020

DOI: http://dx.doi.org/10.20873/uft.2595-7341.2020v3n1p111

A invenção de espaços para a potencialização da vida mostra-se urgente e vital para honrarmos o compromisso social da psicologia com a transformação da realidade social, sobretudo em tempos de incerteza, sofrimento e crise nas instituições escolares.

\section{REFERÊNCIAS}

BOHOSLAVSKY, R. Orientação vocacional: a estratégia clínica. 9 ed. São Paulo: Martins Fontes, 1993.

DELEUZE, G; GUATTARI, F. Mil platôs: capitalismo e esquizofrenia. v. 3. Rio de Janeiro: Ed. 34, 1996.

JARDIM, J. Pro dia nascer feliz. Documentário. Copacabana Filmes, v. 88, 2006.

KASTRUP, V. Aprendizagem, arte e invenção Learning, art and invention. Psicologia em estudo, v. 6, n. 1, p. 17-27, 2001.

NEIVA, K. M. C. Intervenção Psicossocial: aspectos teóricos, metodológicos e experiências práticas. $1^{\mathrm{a}}$. ed. São Paulo: Vetor Editora, 2010.

RACIONAIS MC'S. Sobrevivendo no inferno. Cosa Nostra/Zambia, Brasil, 1997. 1 CD.

SARRIERA, J. C; CÂMARA, S. G; BERLIM, C. S. Formação e Orientação Ocupacional - Manual para jovens à procura de emprego. Porto Alegre: Editora Sulina, 2006. 